\title{
Assessing Dual-Role Staff-Interpreter Linguistic Competency in an Integrated Healthcare System
}

\author{
Maria R. Moreno, M.P.H. ${ }^{\text {}, ~ R e g i n a ~ O t e r o-S a b o g a l, ~ P h . D . ~}{ }^{2}$, and Jeffrey Newman, M.D., M.P.H. ${ }^{1}{ }^{2}$ \\ ${ }^{1}$ Sutter Health Institute for Research and Education, San Francisco, CA, USA; ${ }^{2}$ Institute for Health and Aging, University of California-San \\ Francisco, San Francisco, CA, USA.
}

\begin{abstract}
BACKGROUND: Interpreter services for medical care increase physician-patient communication and safety, yet a "formal certification" process to demonstrate interpreter competence does not exist. Testing and training is left to individual health care facilities nationwide. Bilingual staff are often used to interpret, without any assessment of their skills. Assessing interpreters' linguistic competence and setting standards for testing is a priority.
\end{abstract}

OBJECTIVE: To assess dual-role staff interpreter linguistic competence in an integrated health care system to determine skill qualification to work as medical interpreters.

DESIGN: Dual-role staff interpreters voluntarily completed a linguistic competency assessment using a test developed by a language school to measure comprehension, completeness, and vocabulary through written and oral assessment in English and the second language. Pass levels were predetermined by school as not passing, basic (limited ability to read, write, and speak English and the second language) and medical interpreter level. Five staff-interpreter focus groups discussed experiences as interpreters and with language test.

RESULTS: A total of 840 dual-role staff interpreters were tested for Spanish (75\%), Chinese (12\%), and Russian (5\%) language competence. Most dual-role interpreters serve as administrative assistants (39\%), medical assistants (27\%), and clinical staff $(17 \%)$. Two percent did not pass, $21 \%$ passed at basic level, $77 \%$ passed at medical interpreter level. Staff that passed at the basic level was prone to interpretation errors, including omissions and word confusion. Focus groups revealed acceptance of exam process and feelings of increased validation in interpreter role.

CONCLUSIONS: We found that about 1 in 5 dual-role staff interpreters at a large health care organization had insufficient bilingual skills to serve as interpreters in a medical encounter. Health care organizations that depend on dual-role staff interpreters should consider assessing staff English and second language skills.

KEY WORDS: interpreter services; language proficiency; limited english proficient (LEP); ad-hoc interpreters.
J Gen Intern Med 22(Suppl 2):331-5

DOI: $10.1007 / \mathrm{s} 11606-007-0344-8$

(c) Society of General Internal Medicine 2007

\section{BACKGROUND}

Approximately 49.6 million U.S. residents do not speak the same language as their health care providers, and more than 21 million are considered limited English proficient (LEP). ${ }^{1,2}$ California represents one of the fastest growing LEP populations in the country, with a growth of $42 \%$ between 1990 and 2000. In 2005, $42.3 \%$ of Californians age 5 years and older were considered LEP (speaking English less than well) compared to $19.4 \%$ of the total U.S. population. ${ }^{2}$

Providers' ability to communicate effectively is crucial to the delivery of high-quality health care to patients, especially culturally and ethnically diverse patient populations. ${ }^{3-6}$ Often clinicians turn to bilingual staff for interpretation. Commonly, these dual-role staff interpreters are ad hoc interpreters; untrained in interpretation protocols, medical terminology, or fluency in English or the second language. ${ }^{21}$ Ad hoc interpreters may impair clinical care. ${ }^{7-10} \mathrm{~A}$ recent study revealed that, whereas interpretation errors with potential clinical consequence occurred in $12 \%$ of encounters using trained interpreters, they occurred in $22 \%$ of encounters using untrained interpreters. ${ }^{19}$

Interpretation is a learned skill; whereas it is true that every interpreter can speak at least 2 languages, it does not follow that every bilingual person is an effective interpreter. A provider's ability to accurately diagnose a patient's condition can be jeopardized by unpracticed interpreters who are prone to omissions, additions, substitutions, and volunteered opinions. ${ }^{11-18}$ Ad hoc interpreters, including dual-role staff, family and friends often succumb to the temptation to act as "language brokers" who informally mediate, rather than interpret, information. ${ }^{19}$

Still, current policies are limited and unclear as to what constitutes appropriate language services. In 1964, under the Civil Rights Act (Title VI section 601), the federal government initiated improved services for LEP patients by stating that no person shall "on the ground of race, color, or national origin, be excluded from participation in, be denied the benefits of, or be subjected to discrimination under any program or activity receiving Federal financial assistance." Twenty five years later, under President Clinton, this regulation became more specific for interpreter services. Executive Order 13166 was issued, stating that not-for-profit agencies were required to publish guidance on how they provided meaningful access to LEP persons to comply with Title VI requirements. Similarly, Health 
and Human Services (HHS) developed its own guidance [Section VI.A.-August 30, 2000], addressing considerations relating to interpreter and translator competence:

any health care provider that receives federal financial assistance from HHS (i.e., participating in the Medicare and Medi-Cal programs) must have a process in place to demonstrate fluency of speaking, reading and writing in both English and a second language, including the ability to translate the names of body parts and to competently describe symptoms and injuries in both languages to be considered a "competent interpreter."

Fifty-three years after Title VI was developed, comprehensive guidelines for a "formal certification" process to demonstrate interpreter competence do not exist. The California Healthcare Interpreter Association (CHIA) has developed Standards for Medical Interpreters, which includes a Code of Ethics and the importance of completeness and accuracy. Other private and public organizations have developed "interpreter certification programs" that are all designed for full-time professional interpreters. ${ }^{20}$ Many of these programs are training series that are costly and include 40-60 hours in classroom coursework, which are often not feasible for bilingual health care employees who provide interpreter services as a secondary role in their work environments.

Dual-role staff interpreter testing and training is routinely left to individual facilities, which results in varied quality assurance. A common practice in health care settings in states with high proportions of LEP patients is to hire bilingual staff who can also interpret. This expectation is often unrealistic because bilingual staff are expected to come to the job fully prepared to interpret and yet rarely have actual interpreting experience. Given the complexity of clinical interactions, medical interpreting may be beyond the skills of many bilingual staff. This underscores the need to assess best practices and set a standard for dual-role staff interpreters in health care settings.

To improve language access and quality services for all its patients, a large California health care system of hospitals and medical groups collaborated with a California-based language school to implement a standardized language competence assessment test. This study describes the process and results of assessing dual-role staff interpreters for linguistic competency in 1 health care system.

\section{METHODS}

\section{Setting}

The integrated not-for-profit health care organization involved in this study is comprised of 26 hospitals, 9 medical foundations, and more than 3,000 physicians. It serves 22 counties throughout Northern California, delivering inpatient and ambulatory services to approximately $18.4 \%$ of the state's patients, representing wide cultural, ethnic, and linguistic diversity. According to Census 2000, more than 1.5 million people in the counties served age 5 or older, speak English "less than well" or are LEP. ${ }^{2}$ Among this population, 49\% speak Spanish, 39\% speak Asian languages, and 12\% speak IndoEuropean languages as their primary language.

\section{Participants}

Beginning April 2003, organizational executive staff sent a newsletter with Title VI requirements and language assessment information to more than 150 managers in nursing (22\%), education (5\%), admissions (7\%), emergency (3\%), and technical support (63\%) departments. In turn, the managers completed electronic surveys to identify staff serving as dualrole interpreters who had not previously received formal interpreter training or testing. Approximately 1,200 staff members systemwide were identified as potential candidates for Spanish, Chinese, Russian, Tagalog, Vietnamese, Punjab, and Hmong language testing. Bilingual staff interpreters' primary roles varied, with the majority serving in administrative support or medical assistant roles.

\section{Assessment Procedure}

Recruitment. Supervisors and clinical managers urged staff to take the voluntary Language Competence Assessment Test; incentives were not provided. However, staff was informed that at a future date the exam would be required of everyone whose duties include interpreting. To date, 947 staff members of the 1,200 identified have completed the test, and the current test waiting list shows that nearly all staff has chosen to take the exam.

Language Competence Assessment Exam. Language Dynamics, Inc., a language school established in 1980 in Sacramento, conducted the Language Competence Test. This private company submitted a competitive bid proposal for a language competence assessment test to assess dual-role staff interpreters and was granted the contract. The language school specializes in testing language competence of bilingual-speaking professionals, including administrators, health professionals, and police officers throughout California. This company is used by several California service agencies and health organizations including the police departments of 5 major cities.

The assessment test consists of a written and oral component in English and the second language. The written test assesses completeness, accuracy, and medical terminology; the oral test assesses comprehension and effective communication in the spoken language. It was developed by Language Dynamics, Inc. originally in 1985 with approval from the Office of Civil Rights in San Francisco, and revised in 2000 after the HHS guidelines were published, to fulfill its criteria to test written and spoken competency in both languages, including medical terminology. To develop the linguistic competence test, the language school in collaboration with linguists from the University of California Davis, developed a pool of questions and pretested them at a local public health department. The test was reviewed by managers at different levels of the health department and tested among their health care workers. The language school currently assesses language competence in 10 languages.

Written Test. The first portion of the written competence test consists of 2 medical scenarios in English and the second language to be translated (i.e., "There is a lump on your head where the box hit you. It is possible that you may have suffered a concussion. We would like to take some $\mathrm{x}$-rays of your skull to be sure that there is no fracture. As soon as I examine the results of the $\mathrm{x}$-rays $\mathrm{I}$ will be able to give you a better 
diagnosis.”). The second portion contains 2 lists of medical terminology (i.e., lymph gland, injection, diabetic, and womb) in English and the second language, for translation into the respective language. It is administered classroom-style with a proctor at a system facility with 1 hour to complete.

Oral Test. The oral test consists of a 10-minute conversation with a linguist who asks 14 questions with key medical terminology in both languages, for verbatim interpretation into the appropriate language. Examples include: "Are you feeling any pain? Is it sharp or dull pain?" and "Have you ever had a heart examination where they put a tube from your groin to your heart for x-rays?" The oral test is administered over the phone within 1 month of the written test. As dual-role interpreters in this study are used primarily in a clinical encounter with a medical provider and not for case management or other social needs, the language competence test focuses only on clinical scenarios and terminology.

Assessment Scoring. The test was administered and graded by the contracted company. Grades were determined using both the oral and written tests, to provide an overall score of "no pass", "basic", or "medical". The language school in collaboration with the health care system predetermined passing points.

The test's written component contained 30 questions, allotting 1 point for each question. Each question was scored correct if the translation was accurate, excluding issues of grammar, spelling, and punctuation. The oral component contained 14 questions, allotting 1 point or half a point per question. Staff that interpreted the phrase verbatim received 1 point, or full credit, for the question. A half point was given if the phrase was interpreted as an explanation of the scenario versus verbatim. If the staff omitted the key medical term or could not explain the phrase, the staff received "no credit" for the question.

"Basic interpreter" was defined as demonstrating essential conversational skills in both languages, but unable to effectively read, write, or possess knowledge of medical terminology in English or the second language spoken. To be considered a "Basic" interpreter, staff needed to score at least a $71 \%(10 / 14)$ on the oral, but less than $75 \%(22 / 30)$ on the written portion. Responses were graded on content and accuracy of medical phrases or words, not syntax or ethnic pronunciation.

"Medical interpreter" was defined as those who scored greater than $71 \%(11 / 14)$ on the oral and greater than $75 \%$ $(23 / 30)$ on the written portion. These staff demonstrated the ability to read, write, and speak English and the second language, including medical terminology, at a level that demonstrated college-level competence.

"No pass" was defined as scoring less than $71 \%$ on the oral and less than $75 \%$ on the written test.

Focus Groups. To understand how dual-role staff interpreters were used and to describe their experience in taking the tests and its impact on staff satisfaction, confidence, and validation of their roles as interpreters, a total of 5 focus groups with 155 staff interpreters were conducted. A letter of invitation to participate in the focus groups was sent to all dual-role interpreters who had taken the Language Competence test. Participants represented a total of 8 hospitals and medical foundations, and various language combinations. Spanish/
English was the most frequently used combination. Each focus group lasted approximately 2 hours.

Focus group questions included: What is the process for using a staff interpreter in your affiliate? How did you become a staff interpreter in your affiliate (i.e., volunteer, appointed by manager)? How or who regularly calls your for interpretation? What are the cultural issues you have encountered when interpreting? Do you do other things for the patient, besides interpreting? What are your challenges as a dual-role staff interpreter? What would you need to improve your cultural competence skills? How does your facility support your role as an interpreter? In what ways do you need additional support? How confident do you feel to facilitate patient-physician communication as an interpreter? How does taking the test impact your confidence? What kind of aids would you recommend to use before or during the medical encounter to facilitate physicianpatient communication?

All focus group discussions were conducted in English. The moderators individually reviewed the transcripts of the focus group discussions and identified broad themes.

\section{RESULTS}

Between April 2003 and April 2007, 840 of the approximately 1,200 dual-role staff interpreters completed the linguistic competence assessment, which constituted the study sample. Of the 840 staff tested, $2 \%$ did not pass, $21 \%$ passed at the basic level, and $77 \%$ passed the medical level. Results varied by language tested, with the highest scores among those tested for Tagalog and Vietnamese, and the lowest for those tested for Hmong and Punjab (Fig. 1).

The majority of dual-role staff interpreters spoke Spanish (630, 75\%), Chinese (100, 12\%), and Russian (42, 5\%), and served in a primary role mostly as administrative support (328, $39 \%)$ and medical assistants $(227,27 \%)$. Surprisingly, $17 \%$ (143) of the dual-role staff interpreters were licensed clinicians (i.e., physicians, nurses, therapists). Licensed clinicians did not pass as medical interpreters at higher rates than other bilingual staff; however, more medical assistants tended to pass at the medical interpreter level than administrative support staff, perhaps evidencing their clinical training $(41 \%$ vs $26 \%, p=0.21$ ).

\section{Basic Interpreters}

Basic Interpreters lacked a full grasp of medical terminology and were unable to interpret terms such as "groin", "gall bladder", "stroke", "uterus", or "contractions". Frequently, basic vocabulary in the second language was limited, demonstrated in their inability to interpret regularly used phrases such as, "is your pain dull or sharp?" or "please provide a urine specimen." A common mistake found in the assessment was confusing words with a similar sound but different meaning such as the Spanish word "constipado", which means congested, with the English word "constipated". Additional errors included mixing similar words such as "eye lid" and "eye brow"; "cough" and "flu"; and "measles" and "chicken pox". More serious errors were uncovered such as interpreting the Spanish word for "constipated" to the English word "estranged", "diabetic" to "diabolic", and "measles" to "lice". Often, basic interpreters omitted an entire section of the written exam, which was more frequent among Chinese, Hindi, or 


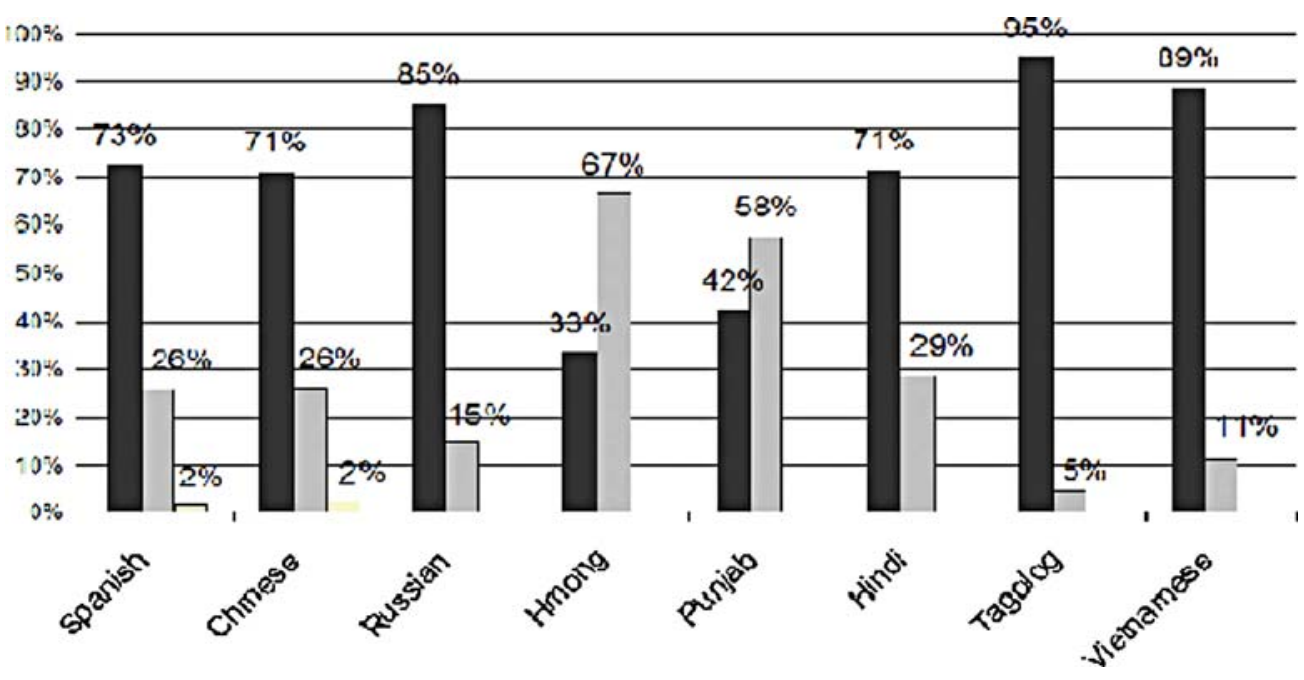

Figure 1. Staff Interpreter Competency Assessment by Language and Qualification

Punjabi staff. Focus group anecdotal evidence shows that this group tends to be second generation immigrants and usually learn to speak informally from their parents and may not read or write the language.

\section{Medical Interpreters}

Medical interpreters were able to maintain effective communication with the tester at the college level and responded correctly to the majority of the key phrases. Most importantly, medical interpreters were able to maintain the conversation flow and exchange of information through clear explanations and correct terminology. Focus group anecdotal evidence suggests medical dual-role staff interpreters were either second generation or first generation immigrants with some educational training in their native country and in the United States. Others had received formal second-language training in college level courses or study-abroad programs.

\section{Focus Groups Results}

Focus groups revealed that many dual-role staff interpreters do not feel confident with their interpreting skills. They reported often feeling rushed and anxious to pace physicians. The staff recommended that the interpreter training course currently available be modified to include additional medical terminology, addressing patients' cultural values, and additional general interpreter skills. Many focus group participants related that the language competence test improved their recognition and validation from coworkers and supervisors. Participants demonstrated minimal dissatisfaction with the test outcomes and change in job responsibilities.

\section{Use of Results}

The health system sent the test results to the staff member and the respective manager and they were placed in the staff's personnel file. Staff that did not pass or passed at the basic level were allowed to retake the exam 6 months later.

Medical interpreters were allowed to interpret for a clinical interaction between a patient and provider at any system facility. Basic dual-role staff interpreters were allowed to interpret only in nonclinical situations such as scheduling follow-up appointments.

\section{DISCUSSION}

This study is the first of its kind to document dual-role language testing and provides an initial step toward developing a standard model for assessing language competence of dualrole staff interpreters. This study found that 1 in 5 dual-role staff interpreters at a large health care system were not sufficiently competent in their bilingual language skills to serve as interpreters in a medical encounter, stressing the importance of language competence testing. Staff interpreters who passed as basic interpreters did not demonstrate the ability to sufficiently speak, read, or write English or the second language. Interpreting errors in a medical setting can result in misinformation, prescription errors, poor treatment adherence, and less patient satisfaction among limited English proficient patients. ${ }^{6}$ Not reading or writing a language can also lead to serious errors, especially in circumstances when staff are asked to translate consent forms, treatment regimens, or follow-up instructions.

Our results support the Joint Commission on Accreditation of Healthcare Organizations' (JCAHO) report on the importance of assuring adequate language services to ensure quality care and patient safety in health care. JCAHO's national study of 60 hospitals revealed that most hospitals do not use professional interpreters, but rather rely on bilingual staff to site-translate informed consent, rewriting, or summarizing consent shortly before the patient's agreement with minimal quality control. ${ }^{20}$ Similarly, whereas several states have passed laws requiring interpreter services or bilingual staff to be available for LEP patients, these laws do not clearly identify requirements for training and language proficiency testing or standards for dual-role interpreters.

The use of bilingual staff has become more common as cultural diversity increases in California and the United States. However, basic interpreters have a limited grasp of medical terminology and low levels of literacy in the spoken languages. Most surprisingly, some dual-role staff interpreters were LEP themselves, lacking the necessary English skills to understand medical providers. Assessment of bilingual staff 
could allow for more appropriate use of their skills and help define dual-role interpreters' skills within a continuum of their interaction with patients.

Further research is necessary to guide legislation and to demonstrate whether assessing interpreters' language competence within the health care setting can impact the quality of care and patient satisfaction. The availability of appropriate assessment tools to measure bilingual language competence of dualrole staff interpreters will allow for correct classification of staff skills and use of those skills within organizations. Our results support the need for staff interpreter testing and curriculum development within a continuum of skills. Through focus groups with staff interpreters, we have learned a great deal about the need to develop a more comprehensive training. We are working on a training that all staff interpreters can complete online while at work in addition to a "Train the Trainer" model with the diversity managers to incorporate quarterly staff round-table discussions. This will enable all staff interpreters to take the training course on their time year-round, ensuring that all staff interpreters receive the necessary training.

There are several limitations to our study, which include a lack of adequate participant data such as country of birth, duration in the United States, education, and age, which limit the ability to assess the relationship of those factors with language competence and generalize our findings. Additionally, we focused only on staff in 1 health care system; family members, friends, and others often play a significant role in ad hoc interpretation. Finally, although the test measures language competence and bilingual skills, it does not measure other critical and subjective components of interpretation including patient advocacy, cultural competence, emotional connectivity, and warmth. Interpreting for specific groups such as elderly LEP patients requires other skills such as patience and understanding, which cannot be captured using this instrument. We were also unable to measure adverse effects (i.e., anxiety or lesser job satisfaction) among staff that were required to stop interpreting for medical encounters as a result of this process. However, results from our focus groups appear to indicate that staff felt more confident with their role as interpreters at both "basic" and "medical" levels.

The test itself does not adequately measure a person's ability to interpret in specific clinical departments such as obstetrics or Internal Medicine, and may need refinement to apply to specialized health care settings. Although this competency test does have face validity, we were unable to conduct sensitivity analysis of the scoring, using multiple "passing scores", which we plan to do in future tests. Finally, the impact of testing interpreters on health outcomes is not known, and therefore we cannot conclude that implementing language testing will change LEP patients' clinical outcomes. These limitations point to the need for further research to develop appropriate standards to provide culturally and linguistically appropriate health care to all patients.

Our findings have significant implications for improving language access among LEP populations. Whereas most dualrole interpreters appear well qualified by our testing, we have also identified an opportunity for improvement. Further research is necessary to validate testing methods, to identify factors associated with interpreter competence, and to assess the impact of interpreter testing and training on patient outcomes. Implementation of best dual-role interpretation practices will expedite improved care for LEP patients.
Acknowledgements: We would like to thank Traci Van and Juan Vallejo, Ph.D. for their valuable insight on the manuscript, and The California Endowment and Sutter Health for their institutional support.

The data presented in this manuscript are original. This manuscript has not been published previously and is not under consideration by another publication. All authors made substantial contributions to the article. All authors have approved the content, wording, and acknowledgments.

Corresponding Author: Maria R. Moreno, MPH; Sutter Health Institute for Research and Education, 345 California Street, Suite 2000, San Francisco, CA 94104, USA (e-mail: morenom@sutterhealth. org).

\section{REFERENCES}

1. http://www.DHHS.gov. October 2006. "Office of Civil Rights Title VI, CLAS".

2. http://www.factfinder.census.gov. April 2007.

3. In the right words: addressing Language and culture in providing Health Care. Grantmakers in Health. 2003 Aug; 18.

4. http://www.iom.edu: Confronting Racial and Ethnic Disparities in Health Care.

5. Yu SM, Nyman RM, Kogan MD, Huang ZJ, Schwalberg RH. Parent's language of interview and access to care for children with special health care needs. Ambul Pediatr. 2004;4(2):181-7 (Mar-Apr).

6. Hornberger JC, Gibson CD Jr., Wood W, et al. Eliminating language barriers for non-English-speaking patients. Med Care. 1996;34(8):845-6 (Aug)

7. Woloshin S, Bickell NA, Schwartz LM, Gany F, Welch HG. Language barriers in medicine in the United States. JAMA. 1995;273(9):724-8.

8. Takka G. Differential access to health care of Latino children in the Hispanic Health and Nutrition Examination Survey. Stanford University, 1991.

9. Kaplan SH, Greenfield S, Ware JE. Assessing the effects of physician interactions on the outcomes of chronic disease. Med Care. 1989;27 (7):679 (Jul).

10. Baker DW, Hayes R, Fortier JP. Interpreter use and satisfaction with interpersonal aspects of care for Spanish-speaking patients. Med Care. 1998;36(10):1461-70

11. Flores G, Laws MB, Mayo SJ, et al. Errors in medical interpretation and their potential clinical consequences in pediatric encounters. Pediatrics. 2003;111(1):6-14.

12. Dye E. Use of translation cards to increase communication with nonEnglish-speaking families in the NICU. Neonatal Netw. 2001;20(7):25-9.

13. Fernandez A, Schillinger D, Grumbach K, et. al. Physician language ability and cultural competence. An exploratory study of communication with Spanish-speaking patients. J Gen Intern Med. 2004;19(2):167-74.

14. Haffner L. Translation is not enough. Interpreting in a medical setting. West J Med. 1992;157(3):255-9.

15. Timmins CL. The impact of language barriers on the health care of Latinos in the United States: a review of the literature. J Midwifery Womens Health. 2002;47(2):80-96.

16. Woloshin S, Schwartz LM, Katz SJ, Welch HG. Is language a barrier to the use of preventive services? J Gen Intern Med. 1997;12(8):472-7.

17. Carr C. National report says language barriers to healthcare may prove costly. Brandeis University, (781) 736-4203, Mark Rukavina, The Access Project, 617-654-9911, x229, Dennis Andrulis, The Access Project, 718270-7726, 2002 (May 2).

18. Juan Vallejo. Language Dynamics Inc., Sacramento, CA.

19. Language Services Resource Guide for Health Care Providers. National Health Law Program and National Council on Interpreting in Health Care. 2007.

20. http://www.jointcommission.org: Joint Commission Report: National Strategies Needed to Better Serve Increasingly Diverse Patient Population in American Hospitals. 2007 (March).

21. Jacobs EA, Lauderdale DS, Meltzer D, Shorey JM, Levinson W, Thisted RA. Impact of interpreter services on delivery of health care to limited-English-proficient patients. J Gen Int Med. 2001;16 (7):468-74. 